\title{
Uma proposta de ensino do eletromagnetismo por meio de atividades experimentais
}

\author{
Angela Michelotti*, Fabricio Luís Lovato**, Elgion Lucio da Silva Loreto***
}

\section{Resumo}

A proposição de atividades que sejam flexíveis e adequadas ao nível cognitivo dos alunos, acompanhadas de reflexão crítica, que permitam o teste livre de hipóteses e sejam decorrentes de problematização constitui-se um método mais eficiente para o ensino-aprendizagem do que a mera transmissão de informações. O Eletromagnetismo é um dos conteúdos em que os estudantes em geral apresentam diversas dificuldades de aprendizagem, apesar de sua importância para a compreensão do mundo cotidiano, visto que os fenômenos elétricos e magnéticos envolvem a grande maioria dos equipamentos de nosso dia a dia. Assim, esse trabalho descreve um conjunto de atividades experimentais realizadas com uma turma de $9^{\circ}$ ano do Ensino Fundamental, levando-se em conta a sua executabilidade pelos próprios alunos, o baixo custo de preparação e a segurança. A partir de um dínamo caseiro elaborado pelos pesquisadores, os alunos executaram, em grupos, 4 experimentos, envolvendo o ato de acender uma lâmpada, o funcionamento de um motor, a condutividade de materiais e relação entre energia e trabalho. O roteiro proposto estimulou a observação, reflexão e elaboração de hipóteses e a revisão de ideias sobre determinados fenômenos.

Palavras-chave: Eletromagnetismo. Experimentação. Ensino de Ciências. Física.

- Doutoranda em Educação em Ciências: Química da Vida e Saúde (Universidade Federal de Santa Maria, RS - UFSM); Mestre em Educação em Ciências: Química da Vida e Saúde (UFSM); Especialista em Educação Ambiental (UFSM); Graduada em Ciências Biológicas - Habilitação Licenciatura Plena (ULBRA- Campus Cachoeira do Sul); Professora da rede municipal de ensino de Santa Maria - RS, Brasil. E-mail: angela_michelotti@ hotmail.com

* Doutor em Educação em Ciências: Química da Vida e Saúde; Mestre em Bioquímica Toxicológica; Bacharel e Licenciado em Ciências Biológicas pela Universidade Federal de Santa Maria, RS. Professor Substituto no Departamento de Metodologia do Ensino da Universidade Federal de Santa Maria, Brasil. E-mail: fabricio. biotox@gmail.com

... Doutor em Genética e Biologia Molecular e Mestre em Genética e Biologia Molecular pela Universidade Federal do Rio Grande do Sul, UFRGS, Porto Alegre, RS; Graduado em Ciências Biológicas pela UFSM, RS. Docente do PPG em Genética e Biologia Molecular da UFRGS; do PPG em Biodiversidade Animal da UFSM e PPG Educação em Ciências UFRGS; UFSM; FURG. Brasil. E-mail: elgionl@gmail.com

Recebido em: 10/11/2019 - Aceito em: 17/01/2020

https://doi.org/10.5335/rbecm.v3i1.10233

http://creativecommons.org/licenses/by-nc-nd/4.0 


\section{Introdução}

Uma percepção de que o interesse pelos estudos e o reconhecimento da autoridade por parte dos alunos é cada vez menor tem crescido entre os professores nas últimas décadas. É difícil para os educadores conseguirem instigar a atenção dos estudantes, pois estes apresentam uma espécie de "bloqueio", especialmente em conteúdos ligados às ciências exatas (FINGER e BEDIN, 2019). Assim, uma mera transmissão de informação já não é mais eficiente como um método adequado de ensino-aprendizagem (SANTOS e SOARES, 2011). O ensino puramente mecânico, que envolve apenas a transmissão de informações, é alvo de crítica também de Delizoicov, Angotti e Pernambuco (2009). Como despertar novamente o interesse dos alunos e produzir um processo de ensino mais eficaz?

Um antigo provérbio chinês atribuído a Confúcio reza que "o que eu ouço, eu esqueço; o que eu vejo, eu lembro; o que eu faço, eu compreendo.” Silberman (1996) adaptou esse provérbio para o seguinte formato: "O que eu ouço, eu esqueço; o que eu ouço e vejo, eu me lembro; o que eu ouço, vejo e pergunto ou discuto, eu começo a compreender; o que eu ouço, vejo, discuto e faço, eu aprendo desenvolvendo conhecimento e habilidade; o que eu ensino para alguém, eu domino com maestria." Tal redação aponta a necessidade de tornar o aluno protagonista de sua própria aprendizagem, desenvolvendo o senso crítico daquilo que lhe é transmitido e as competências que o habilitem a relacionar esses conhecimentos ao mundo real (PINTO et al., 2012).

Para as aulas de Ciências, é mais valioso se ensinar uma série de habilidades relacionadas aos procedimentos de investigação científica do que o "método científico" por si próprio. Algumas dessas habilidades incluem: observação com propósito (busca de padrões); descrição do que é observado; comparações e classificações; formulação de perguntas; proposição de hipóteses explicativas; realização de experimentos; análise de resultados; proposição de explicações para os resultados; desenvolvimento da argumentação; e escrita científica (HARLEN, 2000; HOWE, 2002).

Algumas instituições de ensino têm buscado adotar novas formas de ensino-aprendizagem, reorganizando o seu currículo e procurando integrar a teoria com a prática e o ensino com o serviço (MARIN et al., 2010). O ato de aprender torna-se um processo reconstrutivo, permitindo ao estudante o estabelecimento de diferentes relações entre fatos e objetos, produzindo ressignificações e reconstruções e contribuindo para a sua aplicação em diferentes contextos (DEMO, 2004). 
Campos e Nigro (1999) esboçam uma classificação das atividades práticas. Nas demonstrações práticas, o professor realiza as atividades e o aluno assiste a maior parte do tempo, sem interferências, possibilitando ao aluno maior contato com fenômenos já conhecidos. Os experimentos ilustrativos são executados pelo aluno e cumprem as mesmas finalidades das demonstrações práticas. Nos experimentos descritivos o professor nem sempre tem a obrigação de dirigir. Os alunos têm contato direto com fenômenos que precisam ser apurados, sendo comuns ou não ao seu dia-a-dia. Os experimentos investigativos envolvem obrigatoriamente a discussão de ideias e a elaboração de hipóteses explicativas, as quais são testadas por meio de experimentos. Apenas os experimentos investigativos tornam o aluno ativo na realização da atividade, pois este é estimulado na elaboração e teste de suas hipóteses.

A realização de atividades experimentais fornece a possibilidade de se discutir como a ciência relaciona-se à tecnologia presente no dia a dia dos alunos, as relações sociais associadas à produção do conhecimento científico e as suas implicações ambientais (GONÇALVES e MARQUES, 2006). Tais atividades devem ser flexíveis e adequadas ao nível cognitivo do aluno; acompanhadas de reflexão crítica; devem permitir que os alunos testem livremente suas hipóteses em práticas de caráter investigativo; e serem desenvolvidas em decorrência de uma problematização (AMARAL, 1997).

Refletir sobre situações propostas desencadeia a busca de fatores explicativos e a proposição de soluções para as questões levantadas (ZANOTTO e DE ROSE, 2003). O estudante constrói os conhecimentos, reorganiza o material, adapta-o à sua estrutura cognitiva e descobre as relações, leis e conceitos que precisa assimilar (GARCIA, 1996). O emprego de metodologias práticas na sala de aula estimula a comunicação entre iguais (os alunos entre si), envolvendo a troca de informações, a participação conjunta em atividades, a resolução de desafios e a avaliação mútua (MORÁN, 2015). Alunos envolvidos em atividades investigativas são mais confiantes de suas decisões sobre a aplicação no mundo real dos conhecimentos obtidos (RIBEIRO, 2005).

A Base Nacional Comum Curricular (BRASIL, 2017, p. 343), em relação aos alunos nos anos finais do Ensino Fundamental, declara que 
[...] é importante motivá-los com desafios cada vez mais abrangentes, o que permite que os questionamentos apresentados a eles, assim como os que eles próprios formulam, sejam mais complexos e contextualizados. Além disso, à medida que se aproxima a conclusão do Ensino Fundamental, os alunos são capazes de estabelecer relações ainda mais profundas entre a ciência, a natureza, a tecnologia e a sociedade, o que significa lançar mão do conhecimento científico e tecnológico para compreender os fenômenos e conhecer o mundo, o ambiente, a dinâmica da natureza. Além disso, é fundamental que tenham condições de ser protagonistas na escolha de posicionamentos que valorizem as experiências pessoais e coletivas [...].

O processo de conversão de energia mecânica em elétrica ocorre graças à interação de campos magnéticos rotativos, cuja base científica é o Eletromagnetismo (MACEDO et al., 2011). Os fenômenos elétricos e magnéticos são parte da grande maioria dos equipamentos de nosso dia a dia, como computadores, televisores e geladeiras. Compreender o Eletromagnetismo possui importância fundamental para o entendimento do mundo cotidiano e para o desenvolvimento de uma "educação cidadã" (MAGALHÃES et al., 2002). Assim, esse trabalho objetiva descrever e analisar um conjunto de atividades realizadas com uma turma de $9^{\circ}$ ano do Ensino Fundamental, empregando atividades experimentais e focando-se no desenvolvimento de habilidades de investigação científica, trabalhando-se com conteúdos referentes aos fenômenos eletromagnéticos.

\section{Metodologia}

O foco deste trabalho foi o Eletromagnetismo, devido à presença de seus fenômenos em quase toda ciência da natureza, seu papel como ponto de partida para descobertas fundamentais e para a elaboração de conceitos que conduziram a grandes unificações científicas, além de ser base de muitas tecnologias usadas no nosso dia a dia. A atividade foi realizada com uma turma de 12 alunos do $9^{\circ}$ ano do Ensino Fundamental, em uma escola pública no município de Restinga Seca, RS. A turma era composta por 6 meninos e 6 meninas, com idades variando entre 14 e 18 anos.

Os experimentos desenvolvidos foram selecionados levando-se em conta a possibilidade dos próprios alunos os executarem e utilizando-se materiais de baixo custo, fácil acesso e que proporcionassem segurança no manuseio. $\mathrm{O}$ tempo de execução das atividades também foi levado em conta, executando-se experimentos que não demandassem longos períodos. 
Os pesquisadores confeccionaram um dínamo caseiro para os procedimentos experimentais. Para a sua confecção, foram utilizados os seguintes materiais: tábua de madeira com as dimensões $30 \times 30 \mathrm{~cm}$, pedaço de madeira com as dimensões 3 x 5 x $15 \mathrm{~cm}, 5$ a 7 parafusos, 2 arruelas, 2 pratos plásticos de vasos de plantas (20 cm de diâmetro), um pedaço de cabo de vassoura de madeira $(\approx 15 \mathrm{~cm}), 1$ pequeno motor de 6 a 12 volts (o qual pode ser encontrado em brinquedos infantis como carrinhos, em leitores de CD/DVD e outros objetos elétricos), 1 elástico, 1 braçadeira e/ou pedaço de arrame, 2 fios condutores, 1 dispositivo emissor de luz (LED), pilhas $1,5 \mathrm{~V}$, cola e/ou fita adesiva.

Um dos pedaços de madeira foi utilizado como base do dínamo, enquanto o outro como suporte para se prender o motor. Ambos foram fixados com parafusos. Caso o motor não possa ser preso com o parafuso, pode-se utilizar uma braçadeira e/ou pedaço de arrame para fixá-lo (precisando-se de 2 parafusos extras). Deve-se prender as tampas de plástico unidas pela base, com cola ou fita adesiva. Posteriormente, um pedaço de cabo de vassoura é utilizado para fazer a manivela, devendo ser preso com parafuso, próximo à borda interna das tampas de plástico unidas. Uma arruela é colocada de cada lado das tampas ao prender o parafuso, para poder girar com mais facilidade.

Próximo ao centro da base de madeira deve-se prender com um parafuso as tampas de plásticos unidas. As tampas devem ficar com a manivela voltada para cima. Por fim, um pedaço de elástico deve ser empregado para prender as tampas ao motor, evitando que fique muito tensionado. Do motor sairão dois fios condutores, em um dos quais será preso um dispositivo emissor de luz (lâmpada), conforme a Imagem 01. A Imagem 02 apresenta o modelo de dínamo confeccionado.

Imagem 01: Esquema da ligação dos fios com a utilização de pilhas (esquerda) e sem o uso de pilhas, ao tocar a manivela (direita)
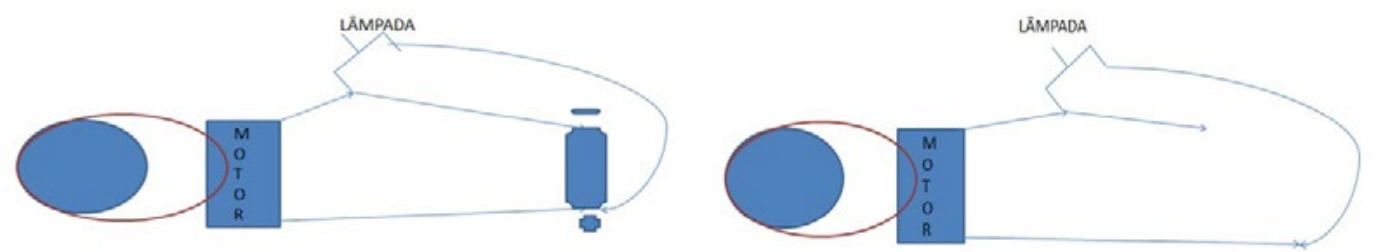

Fonte: elaborado pelos autores. 
Imagem 02: Modelo de dínamo caseiro

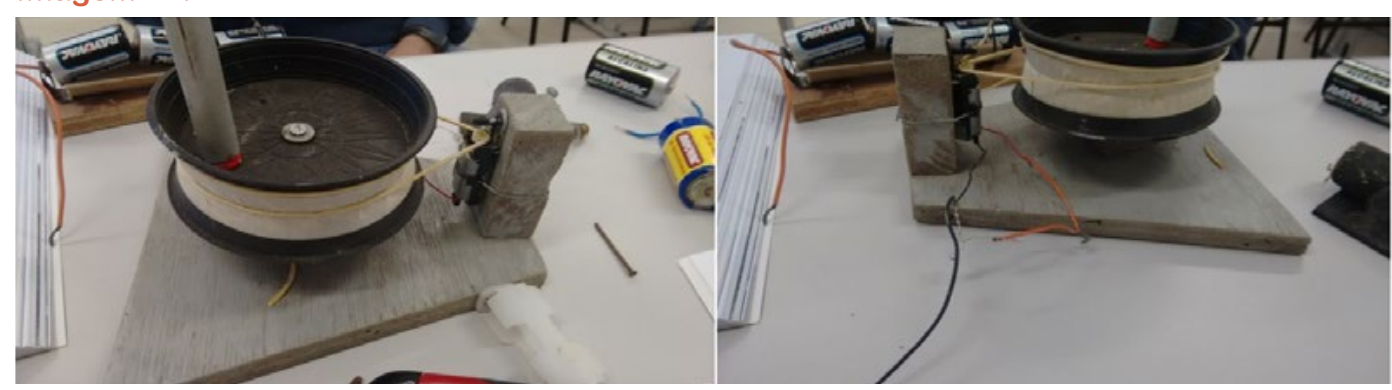

Fonte: elaborado pelos autores.

A atividade aconteceu nas aulas da disciplina de Ciências durante 3 dias, de acordo com a grade da disciplina, totalizando 4 horas-aula. A turma foi organizada em duplas, por afinidade. Os alunos deveriam utilizar seus conhecimentos prévios para tentar executar os experimentos, sem a ajuda de outras duplas. Foram realizados no total 4 experimentos, descritos a seguir.

\section{Experimento 01: É possível acender uma lâmpada?}

Material: 2 pilhas 1,5 V, 2 fios condutores, 1 lâmpada de LED e 1 lâmpada incandescente pequena.

Em um dos fios condutores, a lâmpada foi presa com fita isolante em sua extremidade. $\mathrm{O}$ material foi entregue às duplas, as quais foram questionadas se seria possível acender a(s) lâmpada(s) com estes materiais. Ficou estabelecido que a atividade fosse desenvolvida sem roteiro, deixando que a manipulação do material ocorresse livremente, e que as possibilidades fossem discutidas e testadas pelos alunos.

Objetivo: Os alunos deveriam acender as lâmpadas com estes materiais e perceber as diferenças entre ambas.

\section{Experimento 02: É possivel fazer o motor funcionar?}

Material: 2 pilhas 1,5 V, 2 fios condutores, 1 lâmpada de LED e 1 lâmpada incandescente, um motor pequeno encontrado em driver de CD/DVD.

Neste experimento, foi adicionado aos materiais das duplas apenas o motor. Os alunos foram novamente questionados sobre a possibilidade de se fazer funcionar o motor com os materiais que tinham à disposição.

Objetivo: Analisar se é possível fazer funcionar o motor, apenas com o material recebido. 


\section{Experimento 03: Condutividade?}

Material: 2 pilhas 1,5 V, 2 fios condutores, 1 lâmpada de LED e 1 lâmpada incandescente, um motor pequeno e algumas ferramentas e utensílios, como chave de fenda, facas e tesouras (sem pontas, para que não oferecessem riscos aos alunos).

Foram acrescidos nesta etapa algumas ferramentas e utensílios, e explicou-se aos alunos que nos experimentos anteriores ocorreu a transferência da carga elétrica da pilha à lâmpada/motor, para que o mesmo ligasse/funcionasse. Há materiais que são ótimos condutores de energia e outros que não são condutores de energia, conhecidos como isolantes. Um dos pesquisadores questionou se com estes materiais seria possível descobrir quais materiais são condutores e quais são isolantes, e de que forma o teste poderia ser realizado pelos alunos.

Objetivo: Testar materiais que são condutores ou isolantes de eletricidade.

No decorrer dos três primeiros experimentos, os materiais que não seriam ocupados para o experimento subsequente não eram recolhidos, e os alunos ficavam livres para realizarem outros testes, fora dos solicitados. Dentre os testes adicionais que os alunos realizaram estavam a utilização da bateria do celular no lugar da(s) pilha(s) e a ligação do motor e das pilhas ao mesmo circuito.

\section{Experimento 04: Energia $\times$ Trabalho.}

Material: dínamo caseiro, fios condutores e pilhas de 1,5 V.

Com o material entregue aos alunos, questionou-se como seria possível fazer o dínamo funcionar. Utilizar apenas uma pilha é o suficiente? Ou são necessárias mais? A lâmpada e o motor ligaram ao conectar as pilhas? E se conectarmos a extremidade do fio da lâmpada com a extremidade do fio que sai do motor e girarmos a manivela, a lâmpada acende? O que podemos concluir com a atividade?

Objetivo: Os participantes deveriam fazer o motor funcionar e acender a lâmpada, utilizando as pilhas e sem a sua utilização.

\section{Resultados e discussão}

Em uma conversa prévia aos experimentos, os alunos foram sondados em relação às formas de produção de energia elétrica. Dois alunos indicaram o papel do "movimento" em produzir energia elétrica, e em uma resposta bastante incomum, um dos alunos indicou que "se a gente pega o pente e esfrega na lã produz energia 
por causa da energia estática”. Duas respostas relacionaram a produção de energia com a movimentação humana:

Podemos transformar uma hora de corrida em uma esteira em energia. Eu vi no Youtube.

Se um ser humano corre 100 metros, ele pode tá gerando energia ou perdendo energia. Eu vi na TV.

Essas respostas revelam como os conhecimentos prévios dos alunos, nesse caso suas experiências com vídeos disponibilizados no site Youtube e programações de TV, moldam suas explicações sobre os fenômenos naturais. Em um questionamento sobre a possibilidade de se produzir energia a partir de uma pilha, um aluno declarou que "se juntar duas pilhas com um motorzinho de máquina de fazer tatuagem as pilhas geram energia fazendo com que o motorzinho carregue.” De onde ele obteve essa explicação? Ele próprio fornece a resposta a seguir: "o namorado da minha prima faz isso", indicando novamente que as vivências prévias dos alunos influenciam a maneira como eles observam e interpretam o mundo.

No decorrer da atividade foram realizados quatro experimentos, onde os alunos desenvolveram conceitos práticos. No Experimento 01, o objetivo proposto aos alunos com a atividade era que eles acendessem as lâmpadas com os materiais disponíveis, o que foi realizado com êxito. Os participantes conseguiram intuir que as lâmpadas incandescentes não tinham polos pré-definidos para que elas acendessem, ao realizar a ligação com as pilhas. Já as lâmpadas LED não se acenderiam com a inversão dos polos.

Os alunos perceberem que as luzes das lâmpadas estavam acendendo de forma fraca, e com isso surgiu a ideia de utilizar a bateria do celular, onde pôde-se perceber que as lâmpadas incandescentes e LED acenderam de forma mais intensa. As lâmpadas de LED, se permanecessem ligadas à bateria do celular, queimariam, devido à voltagem da bateria ser elevada. Utilizaram também mais de uma pilha, ligadas em série, concluindo que quanto mais pilhas eram conectadas, mais intensamente a luz das lâmpadas acendia, devido à maior "carga elétrica".

Muitos professores pensam que a função da experimentação no ensino é a comprovação de uma teoria através da prática. $\mathrm{O}$ correto é imaginar o inverso: que através da prática realizada, os alunos consigam chegar por "descoberta" a uma determinada teoria, repensar a teoria estudada anteriormente, ou até mesmo tentar compreender um conteúdo antes da teoria (SILVAe ZANON, 2000). O fato dos alunos 
receberem materiais sem um roteiro estabelecido permitiu a eles criar hipóteses sobre os processos/situações para a utilização desses materiais. Esse contato próximo e a possibilidade de manusear o material desperta maior interesse do aluno e, consequentemente, pode elevar seu envolvimento com o processo de aprendizagem. Na Imagem 3 pode-se ver alunos executando a atividade.

Imagem 03: Alunos realizando as atividades, no Experimento 01
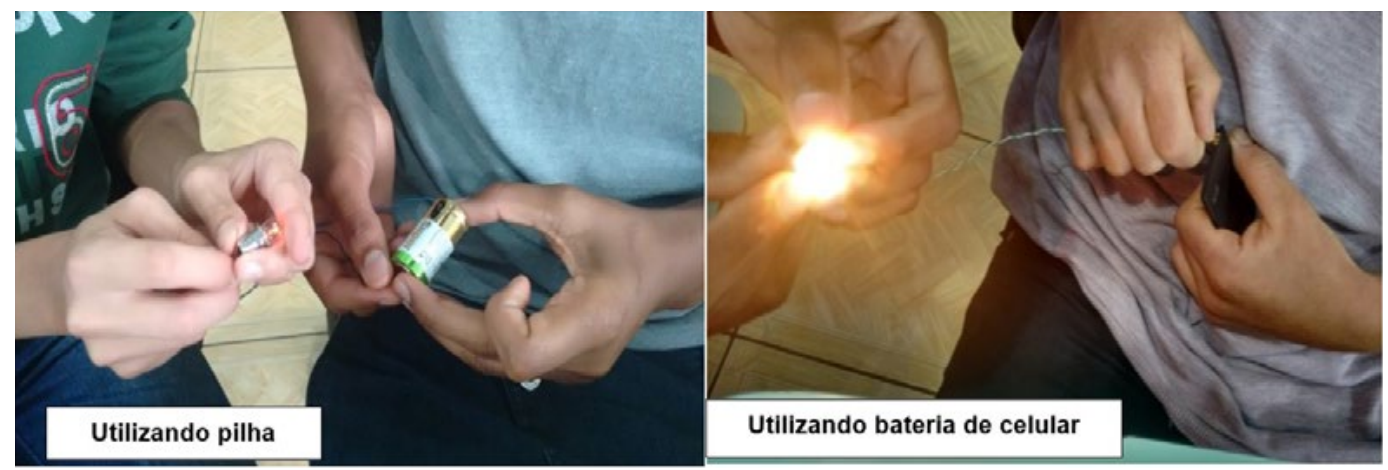

Fonte: autores.

No Experimento 02, foi acrescido ao material o motor. Os discentes atingiram os objetivos propostos, ao conseguirem fazer o motor funcionar com as pilhas. Nesta atividade, as pilhas também foram empregadas em série. Utilizaram novamente a bateria de celular, percebendo-se o aumento de força da rotação do motor.

Um aluno teve a ideia de prender a caneta esferográfica na hélice do motor para averiguar a possibilidade de escrita, conforme se pode observar na Imagem 04. Nas atividades de investigação experimental, os alunos têm a possibilidade de identificar alguma questão interessante a ser resolvida. A solução deve requerer um processo de reflexão e tomada de decisões sobre a sequência dos passos a serem seguidos (CACHAPUZ et al., 2005). 
Imagem 04: Alunos realizando as atividades, no Experimento 02

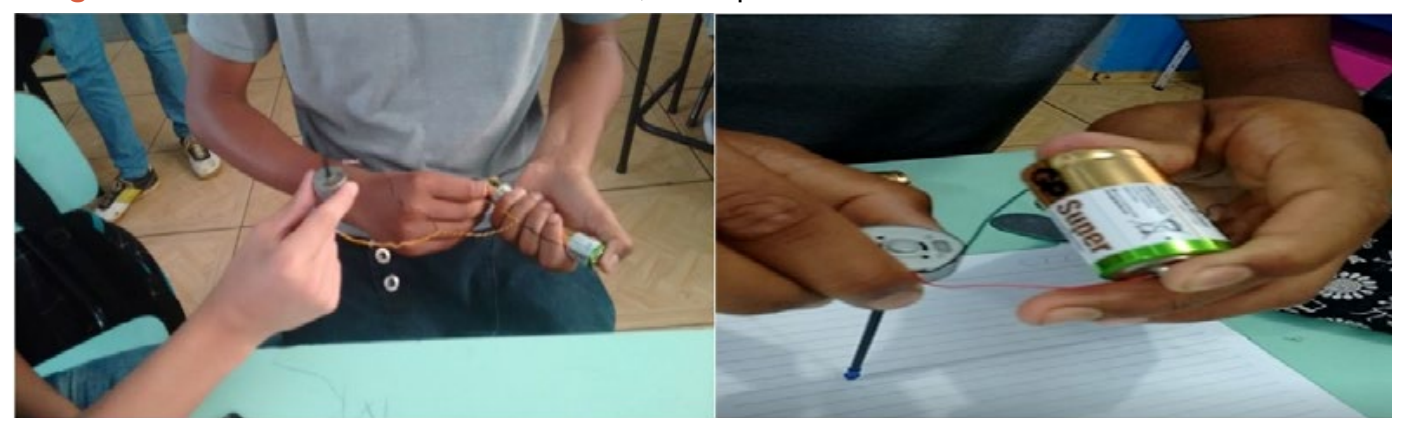

Fonte: autores

Na terceira parte da atividade, no Experimento 03, os alunos foram questionados sobre quais materiais seriam bons condutores de eletricidade, e como isso poderia ser testado com os materiais disponibilizados. Os alunos não souberam responder, então os pesquisadores explicaram que, para acender a lâmpada, deve-se passar uma corrente elétrica vinda das pilhas pelos fios condutores. Se conectarmos as pilhas aos fios condutores e encostarmos a lâmpada e a outra extremidade do fio em uma região metálica, a lâmpada irá acender devido à condução de energia pelo material (metal).

Após a explicação, os alunos utilizaram a técnica para analisar o que poderia ser condutor e o que poderia ser isolante no ambiente da sala de aula. Foram encontrados como condutores: a maçaneta da porta, a parte de ferro da classe, a janela basculante, o chaveiro do estojo de um aluno, a chave de fenda e a parte de metal da faca. Como isolantes, foram encontrados a tábua da classe, o cabo de plástico da faca e a prateleira da sala de aula, devido ser pintada com tinta. A Imagem 05 apresenta fotos do experimento. 
Imagem 05: Alunos realizando as atividades, no Experimento 03

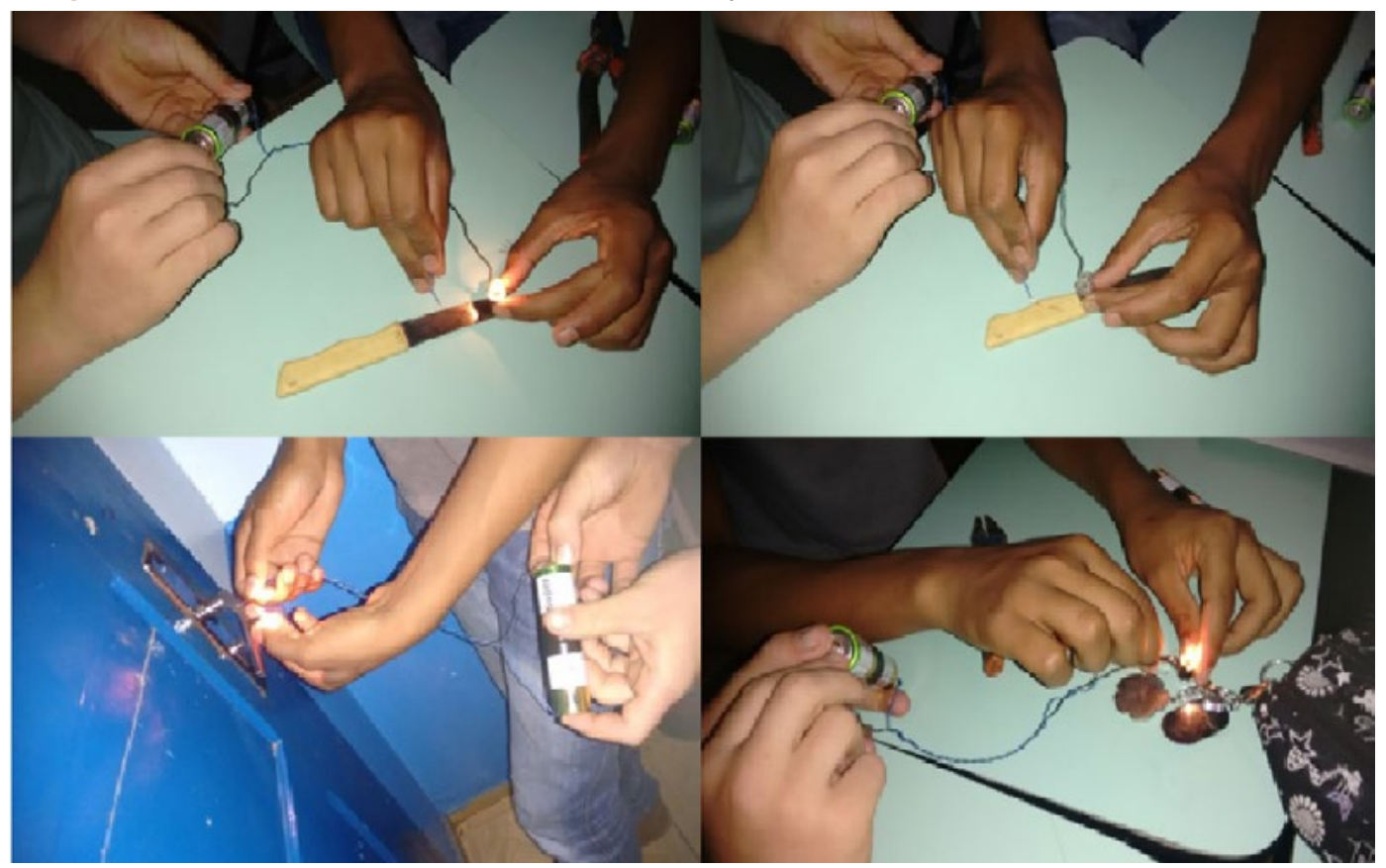

Fonte: autores.

Na última atividade realizada, no Experimento 04, o dínamo foi entregue aos alunos e questionou-se como poderiam fazê-lo funcionar. Eles utilizaram o mesmo princípio para ligar as lâmpadas, no Experimento 01. Ligaram os fios condutores do motor do dínamo às pilhas. Primeiramente, testaram em uma pilha, onde perceberam que nada aconteceu, por não haver força suficiente. Posteriormente, ligaram as pilhas em série, com quatro unidades, percebendo então que o motor realizou trabalho. Foram também feitos testes com a bateria de celular, onde se obteve o mesmo resultado das pilhas em série.

Um dos pesquisadores questionou os alunos durante a atividade, ao ligar as pilhas aos fios condutores, se era possível perceber que há uma transferência de energia, possibilitando que o dínamo realize movimentos/trabalho. Os alunos ficaram na dúvida, realizaram o teste e puderam comprovar a transformação do trabalho manual em energia elétrica, possibilitando que a lâmpada acenda. Durante as aulas experimentais, o professor pode solicitar aos alunos explicações, de forma prévia ou posterior ao experimento, a fim de detectar erros conceituais e concepções alternativas (CARVALHO et al., 2005). 
Os alunos conseguiram comparar esse fenômeno com as usinas hidroelétricas, onde a força da água (energia cinética) faz girar uma turbina, a qual ativa um gerador, que por fim gera energia elétrica; e às usinas eólicas, onde a força do vento faz com que as hélices dos cata-ventos girem, ativando o gerador, que produzirá energia. Os experimentos permitem que os alunos participem de seu processo de aprendizagem, relacionando o seu objeto de estudo com outros acontecimentos e buscando uma explicação causal para o resultado de suas ações e/ou interações (CARVALHO et al., 1999).

Os estudantes em geral apresentam diversas dificuldades de aprendizagem ligadas aos fenômenos do Eletromagnetismo. A noção de campo eletromagnético resulta de uma construção mental amparada em evidências de difícil acesso ao indivíduo no seu dia a dia, não sendo perceptíveis pelos órgãos sensoriais. O que percebemos são as suas manifestações, como uma lâmpada que acende, um ferro que aquece, o rádio que escutamos e a televisão que vemos e ouvimos. Além dessas razões iniciais, há aspectos matemáticos que descrevem esses fenômenos, os quais são de grande complexidade e de difícil compreensão (LODER, 2003).

Para a superação desses obstáculos, pressupõe-se uma dissociação progressiva entre forma e conteúdo, uma vez que o campo não é diretamente observado. $\mathrm{Na}$ melhor situação, podemos observar apenas seus efeitos, que são manifestações das correntes elétricas provocadas pelo campo (como a geração e recepção de uma onda de rádio, o aquecimento térmico e o acionamento de um motor) circulando em circuitos e equipamentos especialmente projetados para os diferentes fins a que se destinam (LODER, 2003). Como transmitir aos alunos essas informações de forma eficiente e relevante para suas vivências?

As escolas públicas ainda são marcadas pela presença das aulas tradicionais. As mudanças sociais têm levado a escola a questionar-se como mudar da prática formal para um ensino relevante, de modo que todos aprendam a conhecer, construir seus projetos de vida e conviver com os demais. É necessária uma revisão nos processos de organização do currículo, metodologias, tempos e espaços (MORÁN, 2015). A aplicação de aulas com atividades mais práticas, como roteiros experimentais, conduz a uma melhor apreciação do conhecimento por parte dos alunos e à assimilação mais significativa dos conteúdos (LIBÂNIO, 2002). Muitas escolas e professores preferem manter os modelos de aulas prontas, mas esses modelos precisam evoluir a fim de incorporar propostas mais centradas no aluno, na colaboração e na personalização (MORÁN, 2015). 
Com o avanço das tecnologias, os estudantes devem ser desafiados com situações em que possam dialogar com novos contextos, onde as atividades não sirvam apenas para resolver um problema sem qualquer utilidade prática à vida. O educando deve vivenciar o próprio processo de construção do conhecimento, o que para Zabala (1998) envolve buscar, descobrir, construir, criticar, comparar, dialogar e analisar. Atividades que possibilitam envolvimento pessoal, alta flexibilidade em sua execução e percepção de liberdade de escolha estão relacionadas ao desenvolvimento da autonomia por parte dos estudantes (BZUNECK e GUIMARÃES, 2010). Quando a combinação de hábitos, conhecimentos e motivação é realizada de forma satisfatória, o aprendiz percebe que a mudança desejada foi causada por ele próprio (GUIMARÃES, 2003).

A utilização desses materiais e das atividades investigativas experimentais possibilitou aos alunos compreenderem alguns conceitos e processos científicos básicos, como corrente elétrica, polos elétricos, voltagem, o uso de baterias para armazenamento de energia, a diferença entre os tipos de lâmpadas, condutividade (materiais condutores e isolantes) e a relação entre trabalho e energia, além de torná-los atuantes ativamente no seu processo de ensino e aprendizagem, construindo juntamente com os colegas e pesquisadores suas definições sobre os temas abordados. Os alunos também passaram a perceber que esses materiais ocorrem em vários equipamentos que utilizam em suas casas, e conseguiram realizar ligações entre o que estava sendo trabalhado em sala de aula e o seu cotidiano. $\mathrm{O}$ emprego de materiais que são facilmente encontrados no dia a dia dos estudantes é um importante ponto de partida para a discussão de conceitos específicos e a busca de uma melhor interação com o mundo material conhecido por eles (SILVA, MISTURA e FOSCHIERA, 2019). A atuação do dínamo foi relacionada à produção da energia que chega a suas casas, oriunda das usinas hidrelétricas. Os mesmos compreenderam que, com a força da água, passando pela turbina, ocorre a geração da energia que é distribuída às nossas residências. Eles conseguiram também fazer a mesma relação com a energia produzida através dos ventos, a energia eólica.

O roteiro experimental tirou os alunos de sua zona de conforto, tornando-os ativos, participativos no processo de ensino e aprendizagem, ao refletirem, testarem e buscarem alternativas para melhor executar o que foi proposto. A problematização pode ser utilizada como estratégia de ensino-aprendizagem nas atividades experimentais. Ela objetiva alcançar e motivar o estudante, que examina e reflete o problema, relaciona à sua história e ressignifica suas descobertas. $\mathrm{O}$ aluno passa a ter contato com 
as informações e a produção do conhecimento, dessa forma solucionando impasses e promovendo o próprio desenvolvimento (MITRE et al., 2008). O professor não possui seu papel enfraquecido, pois é ele quem deve propiciar situações, tanto individuais quanto coletivas, que conduzam às observações, questionamentos, formulação de hipóteses, experimentação, análise, registro e indagações (PAVÃO, 2011).

A melhor forma de aprender é por meio da combinação equilibrada de atividades, desafios e informação contextualizada. A “contextualização do ensino tem relação com a motivação do aluno, por dar sentido àquilo que ele aprende, fazendo com que relacione o que está sendo ensinado com sua experiência cotidiana" (MEDEIROS; LOBATO, 2010, p. 66). Uma sequência didática que envolva o cotidiano do aluno é capaz de elevar o interesse e melhorar a compreensão de temas considerados difíceis (SANTOS, ROSA e BIAZUS, 2018). Quando desejamos aprender a dirigir, não basta apenas lermos muitos livros e artigos sobre o assunto. É necessária, além da teoria, a prática: experimentar o carro, rodar com ele sob supervisão em diversas situações, para, enfim, poder assumir o comando sem riscos (MORÁN, 2015). Para se efetivar a aprendizagem dos alunos, eles devem ser colocados em contato com a natureza, recorrendo-se à observação sistemática, à manipulação controlada, ao estabelecimento de relações complexas entre o objeto da aprendizagem e os aprendizes, com suas atitudes reflexivas no processo de desenvolvimento científico (SILVA e NUNES, 2002).

A experimentação requer dos alunos cuidadosa atenção aos fenômenos ocorridos, aprimorando sua capacidade de observação, fundamental para a compreensão das etapas da atividade proposta e melhora da concentração (CARVALHO et. al., 2005). Giordan (1999, p. 44) destaca a importância das atividades experimentais ao declarar que

[...] a elaboração do conhecimento científico apresenta-se dependente de uma abordagem experimental, não tanto pelos temas de seu objeto de estudo, os fenômenos naturais, mas fundamentalmente porque a organização desse conhecimento ocorre preferencialmente nos entremeios da investigação.

A sociedade do conhecimento baseia-se em competências cognitivas, pessoais e sociais. Essas habilidades não são obtidas de forma convencional, antes, exigem proatividade, colaboração, personalização e visão empreendedora. A escola padronizada distancia-se muito dessa perspectiva, pois ensina e avalia a todos de forma igual, exigindo resultados previsíveis. É possível desenvolver projetos significativos e atividades estimulantes utilizando-se tecnologias mínimas (MORÁN, 2015). A 
experimentação contribui para a melhoria da qualidade no ensino, principalmente por gerar situações de confronto entre as hipóteses dos alunos e as evidências experimentais (MARANDINO; SELLES; FERREIRA, 2009). Mesmo um pequeno número de atividades experimentais, desde que interessantes e desafiadoras, proporcionará um contato direto com os fenômenos, possibilitando a identificação de questões de investigação, a organização e a interpretação de dados, competências essenciais para um ensino efetivo de Ciências às novas gerações (TRIVELATO e SILVA, 2011).

As metodologias devem estar de acordo com os objetivos a serem alcançados. Se a meta é que os alunos sejam proativos, as metodologias devem envolver os alunos em atividades complexas, nas quais tenham de tomar decisões e avaliar os resultados (MORÁN, 2015). O tema da "aprendizagem colaborativa” vem sendo amplamente discutido na literatura de ensino de Ciências, apontando-se de forma crescente para a necessidade de se criar oportunidades para a realização de experimentos em equipe (NURRENBERN e ROBINSON, 1997).

\section{Considerações finais}

Os alunos precisam se tornar os sujeitos de sua própria aprendizagem. Precisamos trabalhar com a realidade dos educandos, partindo dos saberes vivenciais para incorporá-los aos conhecimentos científicos (GUIMARÃES, 2009). O presente trabalho pretendeu apresentar propostas de atividades investigativas experimentais com foco na aquisição de habilidades de investigação científica e aprendizagem dos fenômenos eletromagnéticos. Os experimentos propostos e executados estimulam o raciocínio lógico, propiciando que se relacionem as informações teóricas e os fenômenos observados experimentalmente. Esse tipo de habilidade raramente é desenvolvido nas estratégias de ensino tradicionais. Como aulas experimentais, as atividades estimularam os alunos à observação, reflexão, análise e elaboração de hipóteses, bem como à revisão de suas ideias sobre determinados fenômenos (BIASOTO e CARVALHO, 2007).

Os experimentos contribuíram para a compreensão de conceitos físicos, por meio de uma metodologia que contemplou a reflexão crítica e o desenvolvimento cognitivo através da participação ativa dos estudantes. Os alunos mostraram-se bastante motivados com o trabalho. O ensino e aprendizagem de forma prática tornam-se muito mais prazerosos ao aluno, onde ele, juntamente com o professor, constrói os conceitos e definições sobre o tema estudado. À medida que as atividades 
foram se desenvolvendo, eles discutiam mais entre si as diversas possibilidades de resolução. Isso demonstra que abordar os conteúdos de forma prática e contextualizada permite que os participantes vejam que essas não são questões alheias às suas próprias vivências.

Com simples materiais encontrados em casa, pode-se realizar atividades simples, mas que apresentam grande importância para a construção do conhecimento do aluno, possibilitando a ele vivenciar na atividade prática conceitos que na maioria das vezes são de difícil assimilação e compreensão. Cabe ainda ressaltar que a efetiva participação do aluno durante o processo de construção do conhecimento coloca-o como protagonista de sua aprendizagem, promovendo o desenvolvimento de sua autonomia.

Outro fator importante a ser destacado na atividade proposta foi o papel do professor. Os professores não perderam sua importância, pois foram eles que prepararam e trouxeram os materiais a serem manuseados pelos alunos e propiciaram as situações de discussão, questionamento, hipótese, experimentação e registro, agindo na mediação de todo o processo de ensino-aprendizagem. Torna-se uma responsabilidade do educador organizar-se para empregar e obter o máximo de benefícios das atividades investigativas na formação de seus alunos.

\section{A Teaching Proposal of Electromagnetism Through Experimental Activities}

\section{Abstract}

The proposition of activities that are flexible and adequate to the cognitive level of the students, accompanied by critical reflection, that allow the free test of hypotheses and are due to problematization constitutes a more efficient method for teaching-learning than the mere transmission of information. Electromagnetism is one of the contents in which students in general present several learning difficulties, despite its importance to the understanding of the everyday world, since the electrical and magnetic phenomena involve the great majority of the equipments of our day-to-day. Thus, this work describes a set of experimental activities carried out with a 9th grade elementary school class, taking into account its executability by the students themselves, the low cost of preparation and safety. From a homemade dynamo elaborated by the researchers, the students performed, in groups, 4 experiments, involving the act of lighting a lamp, the operation of a motor, the conductivity of materials and the relation between energy and work. The proposed script stimulated the observation, reflection and elaboration of hypotheses and the revision of ideas about certain phenomena.

Keywords: Electromagnetism. Experimentation. Science Teaching. Physics. 


\section{Referências}

AMARAL, I. A. Conhecimento Formal, Experimentação e Estudo Ambiental. Ciência e Ensino, Campinas, v. 3, p. 10-15, 1997.

BIASOTO, J. D.; CARVALHO, A. M. P. Análise de uma atividade experimental que desenvolva a argumentação dos alunos. ENCONTRO NACIONAL DE PESQUISA EM EDUCAÇÃO EM CIÊNCIAS, 6, Florianópolis, 2007. In: Anais... Florianópolis: ABRAPEC. Disponível em: <http:// www.nutes.ufrj.br/abrapec/vienpec/CR2/p897.pdf>. Acesso em: 21 set. 2019.

BRASIL. Ministério da Educação. Base Nacional Comum Curricular. Educação É a Base. Brasília, DF, 2017. Disponível em: <http://basenacionalcomum.mec.gov.br>. Acesso em: 24 out. 2019.

BZUNECK, J. A.; GUIMARÃES, S. E. R. A promoção da autonomia como estratégia motivacional na escola: uma análise teórica e empírica. In: BORUCHOVITCH, E.; BZUNECK, J. A.; GUIMARÃES, S. E. R. (Org.). Motivação para Aprender: Aplicações no Contexto Educativo. Petrópolis: Vozes, 2010. p. 43-70.

CACHAPUZ, A. et al. A Necessária Renovação do Ensino das Ciências. São Paulo: Cortez Editora, 2005.

CAMPOS, M. C. C.; NIGRO, R. G. Didática de Ciências: o ensino-aprendizagem como investigação. São Paulo: FTD, 1999.

CARVALHO, A. M. P.; VANNUCCHI, A. I.; BARROS, M. A. Ciências no Ensino Fundamental: o Conhecimento Físico. São Paulo: Scipione, 2005.

CARVAlHO, A. N. P. Termodinâmica: um Ensino por Investigação. São Paulo: FEUSP, 1999.

DELIZOICOV, D.; ANGOTTI, J. A.; PERNAMBUCO, M. M. Ensino de Ciências: Fundamentos e Métodos. São Paulo: Cortez Editora, 2009.

DEMO, P. Professor do Futuro e Reconstrução do Conhecimento. Petrópolis: Vozes, 2004.

FINGER, I.; BEDIN, E. A contextualização e seus impactos nos processos de ensino e aprendizagem da ciência química. Revista Brasileira de Ensino de Ciências e Matemática, v. 2, n. 1, p. 8-24, 2019.

GARCIA, J. A. M. Aprendizagem pela descoberta frente à aprendizagem pela recepção: a teoria da aprendizagem verbal significativa. In: COLL, C., PALÁCIOS, J., \& MARCHESI, A. (Org.). Desenvolvimento psicológico e educação. Porto Alegre: Artmed, 1996. p. 68-78.

GIORDAN. M. O papel da experimentação no ensino de ciências. Química Nova na Escola, n. 10, p. 43-49, 1999.

GONÇALVES, F. P.; MARQUES, C. A. Contribuições pedagógicas e epistemológicas em textos de experimentação no ensino de química. Investigações em Ensino de Ciências, v. 11, n. 2, p. 219-238, 2006.

GUIMARÃES, C. C. Experimentação no Ensino de Química: Caminhos e Descaminhos Rumo à Aprendizagem Significativa. Química Nova na Escola, v. 31, n. 3, p. 198-202, 2009.

GUIMARÃES, S. E. R. Avaliação do estilo motivacional do professor: adaptação e validação de um instrumento. 2003. 188 f. Tese (Doutorado em Educação) - Universidade Estadual de Campinas, Campinas, 2003. 
HARLEN, W. The Teaching of Science in Primary Schools. Londres: David Fulton Publishers, 2000.

HOWE, A. Engaging Children in Science. New Jersey: Prentice Hall, 2002.

LIBÂNIO, J. C. Didática. In: Coleção Magistério 2º Grau. Série Formação do Professor. São Paulo: Cortez, 2002.

LODER, L. L. A Aprendizagem e o Ensino do Eletromagnetismo: Dialogando com Piaget e Damásio. XXXI COBENGE - CONGRESSO BRASILEIRO DE EDUCAÇÃO EM ENGENHARIA, 2003, Rio de Janeiro. In: Anais... Rio de Janeiro: ABENGE, 2003. Disponível em: <http://www. abenge.org.br/cobenge/arquivos/16/artigos/CBE087.pdf>. Acesso em: 24 out. 2019.

MACEDO, S. H.; LIMA, J. V.; BIAZUS, M. C. V. Reflexões sobre o Processo de Ensino-Aprendizagem de Eletromagnetismo. In: CARVALHO, A. S. et al. (Org.) Educação e Tecnologia - um percurso interinstitucional. Campos dos Goytacazes: Essentia Editora, 2011. p. 247-261.

MAGALHÃES, M. F.; SANTOS, W. M. S.; DIAS, P. M. C. Uma Proposta para Ensinar os Conceitos de Campo Elétrico e Magnético: uma Aplicação da História da Física. Revista Brasileira de Ensino de Física, v. 24, n. 4, p. 489-496, 2002.

MARANDINO, M.; SELLES, S; FERREIRA, M. Ensino de Biologia: histórias e práticas em diferentes espaços educativos. São Paulo: Cortez, 2009.

MARIN, M. J. S. et al. Aspectos das fortalezas e fragilidades no uso das Metodologias Ativas de Aprendizagem. Revista Brasileira de Educação Médica, v. 34, n. 1, p. 13-20, 2010.

MEDEIROS, M. A.; LOBATO, A. C. Contextualizando a abordagem de radiações no ensino de química. Revista Ensaio, v. 12, n. 3, p. 65-84, 2010.

MITRE, S. M. et al. Metodologias ativas de ensino-aprendizagem na formação profissional em saúde: debates atuais. Ciência \& Saúde Coletiva, v. 13, n. 2, p. 2133-2144, 2008.

MORÁN, J. M. Mudando a educação com metodologias ativas. In: SOUZA, C. A.; TORRES-MORALES, O. E. (Org.). Convergências midiáticas, educação e cidadania: aproximações jovens. Ponta Grossa: UEPG, 2015. p. 15-33.

NURRENBERN, S. C.; ROBINSON, W. R. Cooperative Learning: A Bibliography. Journal of Chemical Education, v. 74, n. 6, p. 623-624, 1997.

PAVÃO, A. C. Ensinar ciências fazendo ciência. In: PAVÃO, A. C.; FREITAS, D. DE. (Org.) Quanta Ciência Há no Ensino de Ciências. São Carlos: EdUFSCar, 2011. p. 15-24.

PINTO, A. S. S. et al. Inovação Didática - Projeto de Reflexão e Aplicação de Metodologias Ativas de Aprendizagem no Ensino Superior: Uma Experiência com "Peer Instruction”. Janus, v. 6, n. 15, p. 75-87, 2012.

RIBEIRO, L. R. C. A Aprendizagem Baseada em Problemas (PBL): Uma Implementação na Educação em Engenharia na Voz dos Atores. 2005. 236 f. Tese (Doutorado em Educação) Universidade Federal de Santa Catarina, Florianópolis, 2005.

SANTOS, A.; ROSA, C. T. W.; BIAZUS, M. O. Abordagem do conceito de função no ensino fundamental partindo da aproximação com o cotidiano. Revista Brasileira de Ensino de Ciências e Matemática, v. 1, n. 2, p. 198-213, 2018.

SANTOS, C. P.; SOARES, S. R. Aprendizagem e relação professor-aluno na universidade: duas faces da mesma moeda. Estudos em Avaliação Educacional, v. 22, n. 49, p. 353-370, 2011. 
SILBERMAN, M. Active Learning: 101 Strategies do Teach Any Subject. Massachusetts: Ed. Allyn and Bacon, 1996.

SILVA, K. A. R. D.; MISTURA, C. M.; FOSCHIERA, E. M. Educação não formal: atividades experimentais em uma cooperativa de catadores. Revista Brasileira de Ensino de Ciências e Matemática, v. 2, n. 1, p. 138-149, 2019.

SILVA, L. H. A.; ZANON, L. B. A Experimentação no Ensino de Ciências. In: SCHNETZLER, R. P.; ARAGÃ̃, R. M. R. (Ed.). Ensino de Ciências: fundamentos e abordagens. Piracicaba: CAPES/UNIMEP, 2000. p. 120-153.

SILVA, S. F.; NÚÑEZ, I. B. O Ensino por Problemas e Trabalho Experimental dos Estudantes Reflexões Teórico-Metodológicas. Química Nova, v. 25, n. 6B, p. 1197-1203, 2002.

TRIVELATO, S. F.; SILVA, R. L. F. Ensino de Ciências. In: CARVALHO, A. M. P DE (Ed.), Coleção Ideias em Ação. São Paulo: Cengage Learning, 2011.

ZABAlA, A. A Prática Educativa: Como Ensinar. Porto Alegre: Artmed, 1998.

ZANOTTO, M. A. C.; DE ROSE, T. M. S. Problematizar a própria realidade: análise de uma experiência de formação contínua. Educação e Pesquisa, v. 29, n. 1, p. 45-54, 2003. 